Analysis

\title{
Material productivity, socioeconomic drivers and economic structures: A panel study for European regions
}

\author{
Marco Bianchi ${ }^{\mathrm{a}, \mathrm{b}, *}$, Ikerne del Valle ${ }^{\mathrm{b}}$, Carlos Tapia ${ }^{\mathrm{c}}$ \\ a TECNALIA, Basque Research and Technology Alliance (BRTA), Astondo Bidea, Edificio700, E-48160 Derio, Bizkaia, Spain \\ ${ }^{\mathrm{b}}$ Department of Applied Economics, University of the Basque Country, Avda. Lehendakari Agirre, 83, 48015 Bilbao, Bizkaia, Spain \\ ${ }^{\mathrm{c}}$ Nordregio, International Research Centre for Regional Development and Planning, Box 1658, SE-111 86 Stockholm, Sweden
}

\section{A R T I C L E I N F O}

\section{Keywords}

Material productivity

Regional productivity

Domestic material consumption

European regions

Economic structures

\begin{abstract}
A B S T R A C T
This paper provides an empirical investigation on the effects that regional economic structures exert on the socioeconomic determinants of material productivity. To this aim, first we develop a taxonomy of economic structures for more than 280 European regions that are classified in four overarching groups: agriculture-, industry-, intermediate- and service-based economies. Second, we perform a panel analysis to explore the impact of economic structures on the relationship between socioeconomic drivers and material productivity, during the period 2006-2015. Our results validate the basic hypothesis of the paper, i.e. the structural relationship between material productivity and its driving factors varies according to the underlying economic structures of the regions. In particular, we found that: (1) an increase in affluence leads to greater material productivity gains in material-intensive regions rather than in areas with service-oriented economies; (2) the degree of urban agglomeration seems to be the most important driver for material productivity, and its leverage effect is bigger among already densely populated regions. Our findings suggest that the influence of socioeconomic factors on material productivity behaves differently according to the idiosyncratic features that regions exhibit. Such diversity translates into different needs and opportunities that local policies should address by adopting a placebased perspective.
\end{abstract}

\section{Introduction}

Searching for sustainable modes of consumption and production represents the only way to meet an ever-increasing demand of goods without incurring in further environmental deterioration. The growing awareness that "business as usual" is both unwise and unsustainable has placed the role of the environment and the efficient use of natural resources at the centre of the political and economic debate (Domenech and Bahn-Walkowiak, 2019). Governments and international organizations are therefore encouraging the adoption of alternative production systems and more inclusive policy models in order to achieve a win-win outcome - a combined environmental and economic benefit (Akenji and Bengtsson, 2014; Steffen et al., 2015).

One of the headline indicators that is systematically reported in empirical works and monitoring frameworks to track the progress towards more efficient and sustainable economies is Material Productivity (MP). MP refers to the economic value extracted from each unit of material resource consumed and it is calculated as the ratio between Gross Domestic Product (GDP) and an indicator of material consumption, generally Domestic Material Consumption (DMC). ${ }^{1}$ The use of DMC as a denominator entails certain limitations that need to be recognised for the correct interpretation of the respective MP measure. Indeed, DMC does not consider hidden material flows related to the use of raw materials at upstream extraction and processing stages. This truncation might lead to wrong interpretations and misleading policy messages, as economies could reduce their DMC by relocating or outsourcing material-intensive activities such as extraction and manufacturing. In this sense, MP indicator frequently becomes more responsive to the structure and sectoral specialisation of a given economy than to its underlying capacity to consume materials in a more efficient and/or

\footnotetext{
* Corresponding author at: TECNALIA, Basque Research and Technology Alliance (BRTA), Astondo Bidea, Edificio700, E-48160 Derio, Bizkaia, Spain.

E-mail address: marco.bianchi@tecnalia.com (M. Bianchi).

1 DMC is calculated according to the Economic-Wide Material Flow Accounting (EW-MFA), a standardized methodology to quantify the amount of materials (i.e.

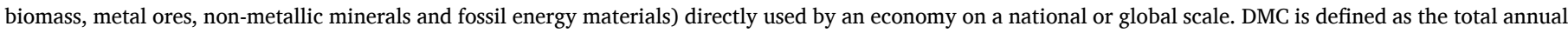
quantity of raw material extracted from the domestic territory, plus all physical imports minus all physical exports (EUROSTAT, 2018).
} 
sustainable way (Fernández-Herrero and Duro, 2019; Gan et al., 2013; Kovanda and Weinzettel, 2013). This shortcoming has been partly addressed by the calculation of Material Footprint indicator (MF), which takes into account the material "rucksacks" associated with imports (Wiedmann et al., 2015). However, up to date MF data are not provided at the country level. Consequently, the DMC-based MP remains the most used indicator not only in empirical studies, but also in policy discourses: The Sustainable Development Goals (SDGs), the G7 Resource Efficiency Alliance, the European Union's Roadmap to a Resource Efficient Europe, the Raw Materials Initiative and the Circular Economy Action Plan are some recent prominent examples of policy initiatives, where the DMC indicator is used to set and monitor policy targets.

Understanding the influential socioeconomic factors driving resource productivity represents the first step in establishing and improving resource management policies (Domenech and BahnWalkowiak, 2019; Flachenecker, 2018; West and Schandl, 2018). Since the 1970s, when the study of socioeconomic metabolism of countries emerged as a new research field, there has been a bourgeoning literature analysing material consumption patterns and MP (FischerKowalski and Haberl, 1998; Fischer-Kowalski and Hüttler, 1998). Among the many research branches focusing on material consumption at the macro-level (see e.g. Zhang et al., 2018 for a literature review), standardized Economic-Wide Material Flow Accounting (EW-MFA) has been the most widely used approach.

A generally accepted conclusion from EW-MFA studies is that MP is higher in high income developed countries and lower in developing countries (Zhang et al., 2018). According to this line of thought, more mature economic structures and minor reliance on material intensive activities, would lead to moderate and stable DMC levels and increasing GDP, mostly through the expansion of the service-based economy (Krausmann et al., 2008). By contrast, MP would be generally lower in developing countries due to the material-intensive processes of urbanization and industrialization, which often characterise these areas (Behrens et al., 2007; Krausmann et al., 2017). This dichotomy reflects the so-called socio-metabolic transition concept (Krausmann et al., 2008), which describes the evolution of material-flows patterns from an economic development perspective. These authors describe MP patterns at national level as a transition process characterised by (1) a shift from an agrarian to industrial phase, where decreased agricultural activity and increased industrial activity lead to higher resource productivity, followed by (2) a shift from industrial to tertiary sector, where decreasing industrial activity and an expanding service sector become the major impetus for resource productivity enhancement (Gan et al., 2013; Pothen and Welsch, 2019). An example of the first phase is provided by the Asia-Pacific region, which between 1990 and 2005 increased its material consumption intensity by nearly $30 \%$, mostly driven by China's soaring industrial and manufacturing capacity (Schandl and West, 2010). On the other hand, structural change of economies towards service sectors can be observed in many advanced economies in Europe, North America and Japan (Giljum et al., 2014; OECD, 2011).

Although the development stages of an economy contribute largely to understanding material consumption patterns, they are far from being the only factors explaining the differences in MP levels observed between regions. As an example, Weisz et al. (2006) found that DMC per capita can be quite different, even among mature economies such as EU15 countries. The authors argue that the level of use of biomass, industrial minerals, ores, and fossil fuels is largely determined by the structure of the economy rather than by national income or economic development. Similar findings were also presented by Bringezu et al. (2004), who examined dematerialisation for industrialised economies, and Dittrich et al. (2011), who examined material use and material efficiency of emerging economies over the years 1985-2005.

The uneven evolutions observed in MP levels led scholars to examine more closely the relationship between MP and its socioeconomic drivers (Gan et al., 2013; Steger and Bleischwitz, 2011; Steinberger et al., 2010). The basic conceptual model employed in the EW-MFA literature for studying the influence of socioeconomic variables on material consumption is constituted by the logarithmic STIRPAT model (Dietz and Rosa, 1997; York et al., 2003). Essentially, this approach seeks to explain environmental Impact (I) in terms of the main socioeconomic influential variables. These are: population $(\mathrm{P})$, affluence $(\mathrm{A})$ and technology $(\mathrm{T})$ (Dietz et al., 2007; Dietz and Rosa, 1994). One of the key advantages of STIRPAT approach is its logarithm specification, which allows to interpret results in the form of elasticities. Over time, several extended STIRPAT models have been proposed. These include a broader range of explanatory variables, from geo-physical, e.g. latitude or climate, to structural factors, e.g. shares of economic activities over total GDP (West and Schandl, 2018). Focusing on recent examples, Robaina et al. (2020) analyse the determinant factors of MP including explanatory variables such as the expenditure on $R \& D$, value added by service and industry sectors or environmental tax revenues. Similarly, Fernández-Herrero and Duro (2019) explore the impacts of socioeconomic drivers in explaining international inequalities in MP levels considering openness to trade and value added by agriculture sector along with the other longestablished explanatory variables.

Regardless of the specificities of different works and the differences in data availability, scholars generally recognise (1) economic status (often referred as affluence and proxied by GDP per capita), (2) economic structure (i.e. value added of specific economic sectors), and (3) demographic structure (i.e. population density) as the most important drivers of MP (Gan et al., 2013; West and Schandl, 2018). GDP per capita usually exhibits a positive relationship with MP as richer economies not only benefit more advanced means for production, but also outsource most of material-intensive products to other areas (Giljum et al., 2014; Wiedmann et al., 2015). Some studies also employ the quadratic term of GDP per capita in order to capture the decreasing marginal utility derived from higher levels of economic status (Fernández-Herrero and Duro, 2019; Steinberger et al., 2013). Therefore, this latter term generally exhibits negative sign. Regarding to the demographic structure, empirical findings suggest that increases in population density lead to higher MP, as more concentrated populations enable agglomeration synergies and high land prices generally 'expel' materially-intensive industries from these areas (Teixidó-Figueras et al., 2016; Weisz et al., 2006). Concerning the economic structures, the effects on MP differ depending on the economic development trajectories mentioned above. It is generally accepted that an expansion of agricultural and primary activities leads to lower levels of MP, while the opposite holds true for the service sector, i.e. increased relevance of services in the economic composition leads to higher levels of MP (Fernández-Herrero and Duro, 2019; Gan et al., 2013).

In general, the narrative on MP and its socioeconomic drivers has been framed within an economic development perspective that tends to juxtapose the higher MP performance of mature economies with the lower MP performance of developing regions. The underlying qualitative nature of economic development has only been marginally addressed by EW-MFA studies despite being widely recognised in neoclassical economic theory at least since Potter et al. seminal work "Competitive Advantage of Nations" (1990). According to this rationale, differences in economic structures, institutions, cultures and historical heritages - often referred to as territorial capital (Castelnovo et al., 2020; Morretta et al., 2020) - all contribute to delineate differential development trajectories (Frenken et al., 2007; Gräbner et al., 2019; Hassink and Klaerding, 2015). These patterns necessarily lead to notable differences in MP patterns but have little to do with the level of economic development. On the contrary, they depend on the available geographically bounded - stocks of physical and human capital. In general, the relevance of territorial assets are more visible at lower territorial levels and often lead to competitive advantages and structurally higher levels of sectoral efficiency (Behrens et al., 2007; Bianchi et al., 2020b). In this context, it can be claimed that it is not entirely possible to understand and interpret the relevance of the spatial distribution of MP unless territorial assets and related structural conditions 
are considered. In this paper, we argue that the structural differences between regional economies are indeed highly relevant for understanding the impacts of socioeconomics drivers on material productivity.

The main contribution of this article is twofold: First, we provide an overview of how the economic specialisations of European regions have evolved over the period 2006-2015; Second, we analyse the relationships between MP and its characterising factors considering the different economic arrangements. The analysis is organized in two phases. In phase one the predominant economic structures are defined for 280 European regions by means of location quotients and clustering techniques. In phase two, we investigate the impact of economic structures on the relationship between MP and its main drivers using a fixed-effects panel analysis. The analysis is performed for the decade 2006-2015, hence a period in which deep economic transformations occurred in Europe due to the financial crisis and its second-tier impacts. The main novelty of this paper focuses on the way in which economic structures are considered in the analysis. Unlike previous works that take account of structural factors as standard explanatory variables in regression models (Fernández-Herrero and Duro, 2019; Gan et al., 2013; West and Schandl, 2018), we consider the economic structures as interaction terms with socioeconomic drivers. This approach allows to characterise the influence of heterogeneous economic structures on the relationships between MP and its socioeconomic determinants.

Our findings support the underlying assumption of this paper, namely that the relationship between MP and its characterising factors change significantly according to the intrinsic economic structures that regions exhibit. In particular, our results suggest the existence of four well-defined economic structures across European regions, including agriculture, industry, intermediate and service-based economies. ${ }^{2} \mathrm{We}$ found that there is a significant difference in the elasticities of socioeconomic drivers between the more material-intensive economies, compared to the less intensive ones. On the one hand, an increase in affluence seems to favour agricultural and industrial economies more than service-based economies. On the other, tertiary economies seem to be able to better capitalise an increase in population density. We also observe a positive impact of R\&D expenditure on MP, but in this case there is no evidence of significant differences of its influence based on the economic structure of regions. Our results strongly suggest that, in order to develop informed policies geared at increased resource efficiency, it is essential to consider the heterogeneous economic configurations of European regions.

The remainder of the paper is organized as follows. Section 2 presents data and methodology employed, while sections 3 and 4 present and discuss empirical results, respectively. Section 5 gives some concluding thoughts and outlines suggestions for further research.

\section{Materials and methods}

This section describes the dataset and the empirical strategy employed. First of all, we classified European regions into four distinct clusters: agriculture, industry, intermediate and service cluster. This classification is assessed by means of specialisation indices (i.e. location quotients) and clustering techniques. Second, we employed a fixedeffects panel to analyse the behaviour of MP socioeconomic drivers across the economic clusters defined. The analysis was performed using R Language and Environment for Statistical Computing (R Core Team, 2020). The data were collected using the R package "Eurostat" v.3.3.5 (Lahti et al., 2019). The cluster analysis was conducted using the R libraries "kmeans" and "hclust" from the "stats" package (R Core Team, 2020). Cluster validation was implemented through "clValide" package

\footnotetext{
2 The names of economic structures refer to the predominant economic activity observed in a region. The intermediate structure refers to those regions that have a rather balanced distribution among the various sectoral branches.
}

(Brock et al., 2008). The econometric analyses were conducted using the R package "plm" described in Croissant and Millo (2008).

\subsection{Data}

The dataset employed in this study comprises a panel data for 280 European regions out of $331^{3}$ at NUTS-2 level ${ }^{4}$ over the period 2006-2015. Data were collected from Eurostat database (access date 1/ $12 / 2019$ ) and it is fully available as supplementary material S2 on the Web. The dependant variable, MP, is defined as the ratio of GDP to domestic material consumption (DMC). MP reflects the GDP generated per unit of resources used by an economy, expressed in $€ / \mathrm{kg}$. DMC accounts for the total amount of materials directly used by an economy, and it is defined as the annual mass of raw materials extracted from the domestic territory, plus all physical imports minus all physical exports. Data on DMC is only available on national level from material flow accounts collected under the regulation (EU) 691/2011 on European environmental economic accounts. Hence, a regionalised version of DMC available from Bianchi et al. (2020a) was used to measure MP at regional level.

The following explanatory variables were selected as the MP driving factors to be analysed: GDP per capita (GDP), Population density (POP) and gross domestic expenditure on $R \& D(R \& D)$. These variables were selected following the literature (see e.g. Fernández-Herrero and Duro, 2019; Gan et al., 2013; West and Schandl, 2018), considering data availability at the regional level. GDP is included in its linear and in quadratic forms. In order to avoid perfect multicollinearity between the two forms, the quadratic term was transformed following the method by Steinberger et al. (2013), as $\left(\log (G D P)-\right.$ mean $(\log (G D P))^{2}$. POP is expressed as the number of inhabitants per square kilometres, while $R \& D$ is measured in percentage of the country GDP. R\&D is widely used to assess whether the productivity of a region is sensitive to investments in innovation activities. While empirical findings generally agree on the positive effects that R\&D exert on economic measures of productivity, $i$. e. GDP over employment or hours worked (Bravo-Ortega and García Marín, 2011), the relationship between R\&D and MP is not so straightforward. For example, recent studies found that R\&D has different impacts depending on the speed of growth of the economies considered (Robaina et al., 2020). Therefore, less developed economies having larger margin for improvements seem to benefit more from R\&D investments. Similarly Kancs and Siliverstovs (2016) found that the relationship between $R \& D$ expenditure and productivity growth might be non-linear as there exist important inter-sectoral differences with respect to $R \& D$ investment and firm productivity. Accordingly, we also included the quadratic term of $\mathrm{R} \& \mathrm{D}$, computed as (log $(\mathrm{R} \& \mathrm{D})-$ mean $(\log (\mathrm{R} \& \mathrm{D}))^{2}$.

Next to MP and the explanatory variables, the gross value added by economic sectors (GVA) was also included to characterise regional economic specialisation (See following Section 2.2).

\footnotetext{
${ }^{3}$ Regions of Albania, Bosnia and Herzegovina, Iceland, Lichtenstein, Montenegro, Serbia, Turkey, Republic of Kosovo and French outermost regions were excluded from this study because of missing data. Inner London West (UK) was also excluded from the study because it represents an outlier, being its GDP per capita more than 6 times the European average.

4 The NUTS system was established by EC Regulation 1059/2003 that defined a common classification of territorial units for statistics (NUTS), based on the administrative divisions applied in the Member States. The 2nd level in the classification (NUTS 2) groups regions with population between 80,000 and 3 million. In this paper we refer to the nomenclature NUTS 2, year 2013. Recently a new NUTS 2 classification has been issued, however we preferred to employ the older one as data for year 2006 are not available according to the new nomenclature for certain countries.
} 


\subsection{Regional cluster identification}

The main goal of this phase is to define a taxonomy for the different underlying structures of the 280 regional economies in the 2006-2015 period. In order to capture and characterise the underlying productive structure of each region we first computed the Location Quotients (LQs). Differently from the GVA share, which simply indicates the relationship between an industry and the whole economy, the LQs reveal which industries make the regional economy unique, or in other words, what is the sectoral specialisation of a region in comparison to a National or international benchmark. We computed LQs for selected economic activities (NACE rev.2), namely: agriculture (A), industry (B-E) and services (G-J + K-N), ${ }^{5}$ using the GVA generated by each of the economic branches. We also considered the inclusion of building and construction as a fourth economic segmentation. However, since this latter branch is rather homogenous across the sample and did not contribute significantly to distinguish regional economies, we decided to drop it.

As said, LQs are computed as a ratio that compares a region to a larger reference region according to some characteristic or asset (e.g. employment shares or GVA shares based on industrial activities). Hence, if for example, $x$ is the GVA generated by sector $k$ in a region $i, y$ is the GVA generated by the whole economy in a region $i$, and $X$ and $Y$ are similar data points representative of European average, then the LQ or relative concentration of asset $k$ in the region $i$ compared to Europe is:

$L Q_{i, k}=\frac{x_{i, k} / y_{i}}{X_{E U, k} / Y_{E U}}$

The use of LQs not only translates into very defined regional groups, but is also conductive to the economic phases that are usually referred in evolutionary studies that consider the different development stages of territories (Fernández-Herrero and Duro, 2019; Gan et al., 2013; Krausmann et al., 2008). High LQs in primary or secondary activities typically reflect export-oriented economies. The economic relevance of export activities is largely discussed in the literature (see e.g. Lee (2011) for a literature review). Studies using aggregated metrics of specialisation acknowledge that exporters are, on average, more productive than nonexporting areas. However, scholars also emphasise that productivity levels depend on the specific production structure of economies and, therefore, on the types of exports (Feenstra and Kee, 2008). In general, industries exporting relatively "low-tech" products show inferior levels of material productivity as they carry out most of the material-intensive activities related to extraction and/or primary processing of raw materials in situ.

In a second step, we proceeded to the definition of a taxonomy of regional economic structures. Identifying the predominant economic activity is straightforward for many regions. This is for example the case of most capital regions, which virtually in all cases are highly urbanised areas with service-based economies. However, intermediate regions exhibit a rather complex combination of economic activities, which ultimately prevents a transparent classification without incurring in subjective judgement and knowledge bias. In addition, we were also interested in capturing the structural changes occurred during the decade covered in our study (from e.g. prevalent industrial configurations to service economies, or vice-versa). This increased the complexity of performing a regional classification, as we could not infer regional structures to the entire panel based on a one-year analysis, nor we could treat each year separately, as fundamental changes at European level might change the classification of a region independently from its intraregional patterns.

For these reasons, we pooled our data and applied alternative clustering techniques to identify a number of quantitatively robust groups of regions. This approach allowed to significantly reduce the complexity of the analysis focused on more than 2600 observations. Following Gräbner et al. (2019) and Steinberger et al. (2013), we relied on two conventional cluster techniques, hierarchical clustering (HCA) and k-means analysis. ${ }^{6}$

The final clustering approach and resulting number of regional clusters was established based on standard internal cluster validation procedures, such as the Connectivity (Handl et al., 2005), the Silhouette Width (Rousseeuw, 1987) and the Dunn Index (Dunn, 1974). In addition, since clustering techniques are purely inductive ways of analysing data that do not exploit theoretical insights other than those involved in variable selection, we validated our cluster results by comparing clusters features with theoretical assumptions and other classifications used in the literature.

\subsection{Panel data modelling approach}

Once identified the underlying economic structure for each region, we proceed to test the impact of the latter on the relationship between MP and socioeconomic drivers. To the authors' knowledge, this specific aspect has not yet been addressed by previous studies. Therefore, for the sake of completeness, we present in Table 1 the summary of the functional forms employed. These considers the economic structures as (1) indexes (IND), (2) exogenous variables independent from other socioeconomic drivers (EXO) and interaction terms (INT). Due to space limitations, we only present empirical results for approaches EXO and INT, since IND approach presents some methodological shortcomings that limit a consistent comparison. The reader can refer to the supplementary material $\mathrm{S} 1$ for the complete set of results. Note also that all specification models are in logarithmic form. This allows to reduce skewness and

Table 1

Summary of panel modelling approach.

\begin{tabular}{|c|c|}
\hline Model acronym & Model description \\
\hline $\begin{array}{l}\text { IND-Economic structures as } \\
\text { INDexes (Pooled) }\end{array}$ & $\begin{array}{l}\text { Separate model fitted to the data for each } \\
\text { economic structures (j). Each model } \\
\text { parameter is sample-specific. Comparison of } \\
\text { parameters between different economic } \\
\text { structures is not consistent. }\end{array}$ \\
\hline \multicolumn{2}{|c|}{$\begin{array}{c}\log \left(M P_{i t j}\right)=\alpha_{i}+\beta_{1} \log \left(G D P_{i t}\right)+\beta_{2} \log \left(G D P_{i t}\right)^{2}+\beta_{3} \log \left(\text { Pop }_{i t}\right)+\beta_{4} \log \left(\mathrm{R} \& \mathrm{D}_{i t}\right)+\beta_{5 j} \\
\log \left(\mathrm{R} \& \mathrm{D}_{i t}\right)^{2}+\varepsilon_{i t}, \text { for each } j=1, \ldots N \text { clusters }\end{array}$} \\
\hline $\begin{array}{l}\text { EXO-Economic structures as } \\
\text { EXOgenous variables (Fixed- } \\
\text { effects) }\end{array}$ & $\begin{array}{l}\text { The effects of economic structures are } \\
\text { absorbed into the exogenous factors }\left(\beta_{j} j_{i t}\right) \text {. } \\
\text { The indirect impact on socioeconomic drivers } \\
\text { is disregarded. }\end{array}$ \\
\hline \multicolumn{2}{|c|}{$\begin{array}{c}\log \left(M P_{i t}\right)=\alpha_{i}+\beta_{1} \log \left(G D P_{i t}\right)+\beta_{2} \log \left(G D P_{i t}\right)^{2}+\beta_{3} \log \left(P o p_{i t}\right)+\beta_{4} \log \left(\mathrm{R} \& \mathrm{D}_{i t}\right)+\beta_{5} \\
\log \left(\mathrm{R} \& \mathrm{D}_{i t}\right)^{2}+\beta_{j} j_{i t}+\varepsilon_{i t},\end{array}$} \\
\hline $\begin{array}{l}\text { INT-Economic structures as } \\
\text { INTeraction terms (Fixed-effects) }\end{array}$ & $\begin{array}{l}\text { The effect of economic structures directly } \\
\text { influences the socioeconomic drivers. } \\
\text { Comparison of socioeconomic drivers across } \\
\text { different economic structure can be done } \\
\text { consistently. }\end{array}$ \\
\hline
\end{tabular}

$\log \left(M P_{i t}\right)=\alpha_{i}+\beta_{1} \log \left(G D P_{i t}\right) \times j_{i t}+\beta_{2} \log \left(G D P_{i t}\right)^{2}+\beta_{3} \log \left(P o p_{i t}\right) \times j_{i t}+\beta_{4} \log (\mathrm{R} \&$ $\left.\mathrm{D}_{i t}\right) \times j_{i t}+\beta_{5} \log \left(\mathrm{R} \& \mathrm{D}_{i t}\right)^{2}+\varepsilon_{i t}$

Note: $i=1, \ldots n$ is the individual (region) index; $t=1, \ldots z$ is the time index; $\alpha_{i}$ is the intercept and $\beta_{1}, 2, \ldots, 5$ are the parameters (in this case interpretable as elasticities); $\varepsilon$ is the error term.

\footnotetext{
${ }^{5}$ The acronyms refer to the NACE rev. 2 taxonomy (European Commission, 2013). Service category includes financial and insurance activities; information and communication activities, real estate activities; professional, scientific and technical activities; administrative and support service activities.
}

\footnotetext{
${ }^{6}$ See supplementary material S1 for further details on hierarchical clustering and $\mathrm{k}$-means techniques.
} 
approximate linear relationships between variables. The log-log form also allows to interpret the parameters' coefficients $(\beta)$ as "ecological elasticities" (York et al., 2003).

The IND approach consists in considering separate models fitted to the data for each regional cluster $j$. In this way specific elasticities are estimated for each cluster. However, since this process is carried out separately for each group of regions, the comparison of parameters between different clusters is not straightforward. In addition, IND can only be estimated through a pooled model, as we lose the panel structure. In fact, the regional sample for each economic cluster changes for each year, following variations in the economic specialisation of the regions. The EXO approach estimates the average impact of regional economic structures on MP. This is the approach that is generally found in existing literature (Fernández-Herrero and Duro, 2019; Robaina et al., 2020). In this case, economic structures are included in the model as an additional independent explanatory variable, but the extent to which economic structures influence other socioeconomic drivers is disregarded. Finally, our approach INT introduces the economic structures through the interaction term $x_{i} \dot{j}_{i t} \beta_{i t}$, which measure the impact $\beta$ of a socioeconomic driver $x$ according to the regional economic structure $j$.

Differently from the alternative models, the INT approach allows to consistently compare the effects of socioeconomic drivers on MP across the different economic structures. In other words, the INT approach allows to assess whether socioeconomic parameters differ significantly from each other as regional economic structures change. A statistic based on the $t$ distribution is used to test the two-sided hypothesis that a slope $\beta_{j 1}$ of a cluster $j_{1}$, equals a slope $\beta_{j 2}$ of a cluster $j_{2}$. The statements for the hypothesis test are expressed as:

$H_{0}: \beta_{j 1}=\beta_{j 2}$

$H_{1}: \beta_{j 1} \neq \beta_{j 2}$

The test statistic used is $T_{0}=\frac{\widehat{\beta}_{j 1}-\widehat{\beta}_{j 2}}{\operatorname{se}\left(\widehat{\beta}_{j 1}\right)}$, where $\widehat{\beta}_{j 1}$ is the least square estimate of $\beta_{j 1}$, and $s e\left(\widehat{\beta}_{j 1}\right)$ is the standard error. The test statistics, $T_{0}$, follows a $t$ distribution with $(n-2)$ degrees of freedom, where $n$ is the total number of observations. The null hypothesis is accepted if the calculated value of the test statistic is such that $-t_{\frac{\alpha}{2}, n-2}<T_{0}<t_{\frac{\alpha}{2}, n-2}$, where $t_{\frac{\alpha}{2}, n-2}$ is the percentile distribution of the $t$ distribution corresponding to a cumulative probability of $(1-\alpha / 2), \alpha$ is the significance level, and $-t_{\frac{\alpha}{2}, n-2}$ and $\frac{t_{2}, n-2}{2}$ are the critical values for the two-sided hypothesis.

Similarly to previous studies performing panel analyses on equivalent socioeconomic datasets (e.g. West and Schandl (2018)), we found that the pooled model and the random effects model were unlikely to provide valid results for EXO and INT approaches. Not surprisingly, the most meaningful results from panel analyses were those obtained using the fixed-effects model. Further details on panel data models along with the decisional flow employed to select the most appropriate model are provided in the supplementary material $\mathrm{S} 1$.

\section{Results}

\subsection{The taxonomy of regional economic structures}

Due to space limitations, we only present the results for clusters based on k-means approach, which overall constituted the bestdifferentiated and comprehensive nomenclature for regional economic structures in Europe. The reader can refer to the supplementary material S1 for the whole set of results and comparison of clusters analysis. Table 2 provides the summary statistics for the economic specialisations and socioeconomic variables according to the regional taxonomy defined. Cluster (1) encompasses the economies strongly specialised in agricultural sectors and presents an average agriculture's LQ greater than 4. This means that, in regions belonging to this cluster, agriculture is four times more concentrated than the European average. It should be noted that this cluster also features the lowest population density (roughly $70 \mathrm{hab} / \mathrm{km} 2)$ and the lowest GDP per capita $(\sim € 18,000$ per capita (PPS) ${ }^{7}$ in 2015). Cluster (2) comprises the regions with the highest specialisation in industrial sectors (LQ industry $~ 1.7$ ). These regions are also specialised in material intensive activities and are characterised by lower levels of population density and GDP per capita with respect to European average. Cluster (3) groups intermediate economies, i.e. those presenting similar LQs across all sectors, falling close to the European average. Finally, economies specialised in the service sector are gathered in cluster (4). Service-based economies usually develop in very densely populated areas, where the lack of available land impedes the proliferation of material-intensive activities. All in all, cluster (4) presents the highest scores for population density, GDP per capita and MP.

Fig. 1 provides a geographical distribution of regional economic structures at the beginning (2006) and at the end (2015) of our studyperiod, while, in Fig. 2, we show the respective regional patterns for MP. In line with previous studies (Fernández-Herrero and Duro, 2019), a significant improvement in MP can be observed across most of European regions between the two periods. As shown in Table 2, this progress was generalized, even if it occurred at different pace depending on the structural features of regions.

Comparing the evolution of economic structures (Fig. 1) and MP (Fig. 2), we see that a structural change towards material intensive sectors not necessarily translates into lower MP levels if such transformations are coupled and/or based on more efficient technologies. Ireland is an outstanding example of such structural change, as it went from an intermediate economic structure in 2006 to a very industrialised one in 2015, being its industrial LQ among the highest in Europe (2.08). In fact, the manufacturing share of GVA of Southern and Eastern Irish regions increased threefold over the period considered. Nonetheless, these regions also improved their MP rates (0.98 in 2006 and 2.88 in 2015). The same can be said for the southern Spanish regions Andalucía and Murcia, which exhibited among the highest MP increase between 2006 and 2015 (roughly 10\%) despite a structural shift towards agricultural specialisation (agriculture LQ for Andalucía and Murcia equal to 4.16 and 3.44 in 2015 respectively). Conversely, many European eastern regions showed reversed trajectories, i.e. from primary agriculturalbased economies to industrial, intermediate and service -based economies. As an example, Southwestern region of Bulgaria, where the capital Sofia is located, is clearly evolving towards a service-based economy comparable to most European capitals. A similar situation can be observed in Bucharest, while other Romanian areas such as Northwest, Central and West region transitioned towards predominant industrial structures.

The taxonomy defined also illustrates very well the spatial agglomeration patterns of manufacturing activities towards the so-called "Central European Manufacturing Core" (Stehrer and Stöllinger, 2015). This area is led by German regions and includes large portions of Austria, the Czech Republic, Slovakia, Hungary and Poland. In all these regions the concentration of manufacturing activities increased significantly since the 2000 s, probably as a response to expanding market shares in manufacturing industries (Cutrini, 2019). Stehrer and Stöllinger also reported a significant decline in manufacturing for most other European countries (in particular high-income countries, such as the Nordics and Benelux area, alongside France and United Kingdom). This trend is also reflected in Table 2 and Fig. 1.

\footnotetext{
7 The purchasing power standard (PPS) is the technical term used by Eurostat to indicate the common currency adjusted for price level differences across countries.
} 
Table 2

Summary statistics of Location Quotients (LQs), population density (POP), GDP per capita (GDP) and material productivity (MP) by regional clusters.

\begin{tabular}{|c|c|c|c|c|c|c|c|c|c|c|c|c|}
\hline \multirow[t]{2}{*}{ Cluster } & \multicolumn{2}{|c|}{ LQ Agriculture } & \multicolumn{2}{|c|}{ LQ Industry } & \multicolumn{2}{|c|}{ LQ Services } & \multicolumn{2}{|c|}{ POP (hab/Km2) } & \multicolumn{2}{|c|}{ GDP (PPS/hab) } & \multicolumn{2}{|c|}{ MP (PPS/Kg) } \\
\hline & 2006 & 2015 & 2006 & 2015 & 2006 & 2015 & 2006 & 2015 & 2006 & 2015 & 2006 & 2015 \\
\hline 1 Agriculture & 5.16 & 4.72 & 1.13 & 1.12 & 0.78 & 0.80 & 68 & 65 & 14,494 & 18,376 & 0.79 & 1.33 \\
\hline 2 Industrial & 1.48 & 1.53 & 1.65 & 1.70 & 0.75 & 0.74 & 149 & 144 & 22,766 & 27,174 & 1.21 & 1.63 \\
\hline 3 Intermediate & 1.26 & 1.23 & 1.04 & 1.03 & 0.93 & 0.93 & 245 & 260 & 24,155 & 27,852 & 1.49 & 2.29 \\
\hline 4 Services & 0.69 & 0.67 & 0.60 & 0.57 & 1.17 & 1.18 & 1067 & 1167 & 30,301 & 34,308 & 2.22 & 3.23 \\
\hline
\end{tabular}

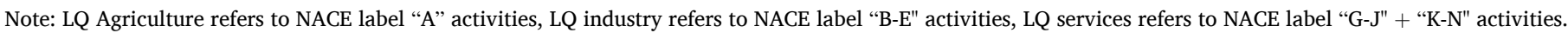
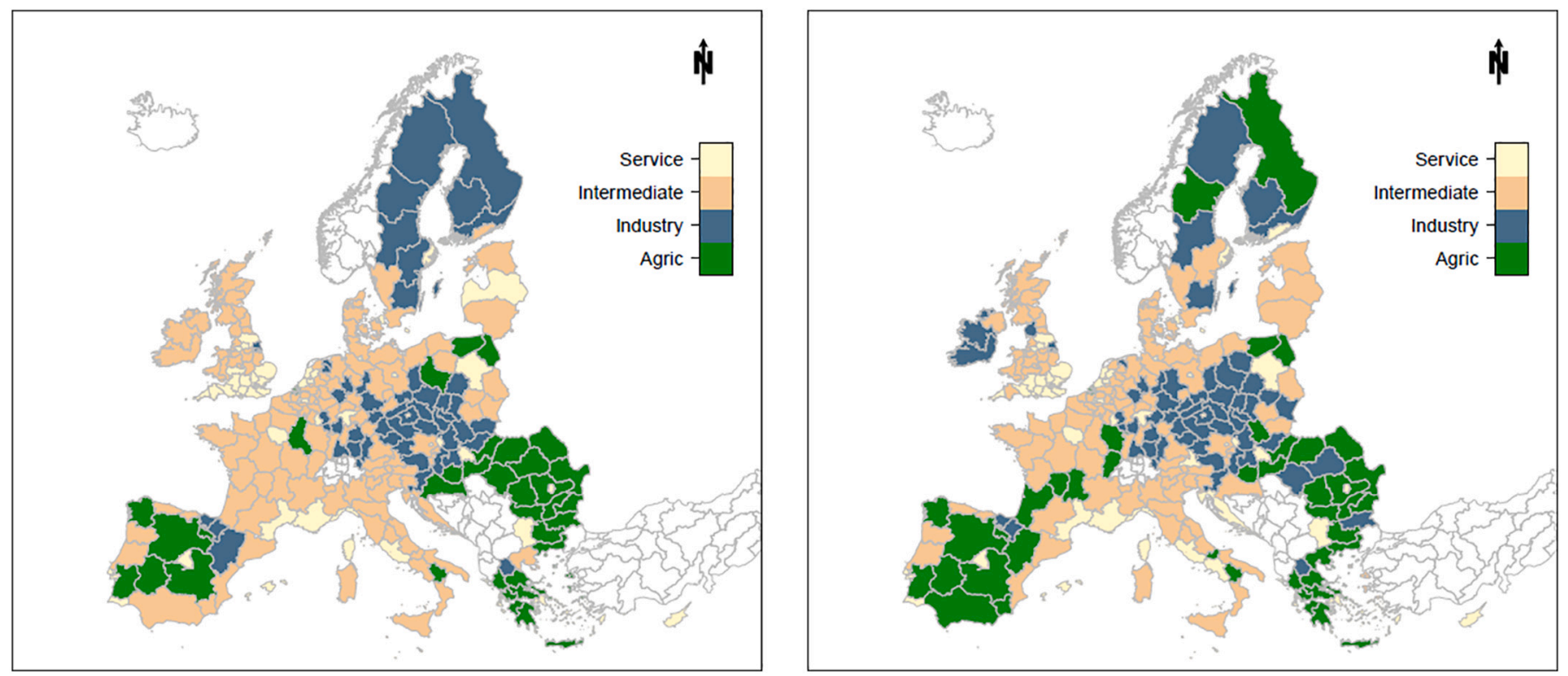

Fig. 1. The geography of regional economic specialisations in 2006 (left map) and in 2015 (right map). Note: White regions indicate no data availability.
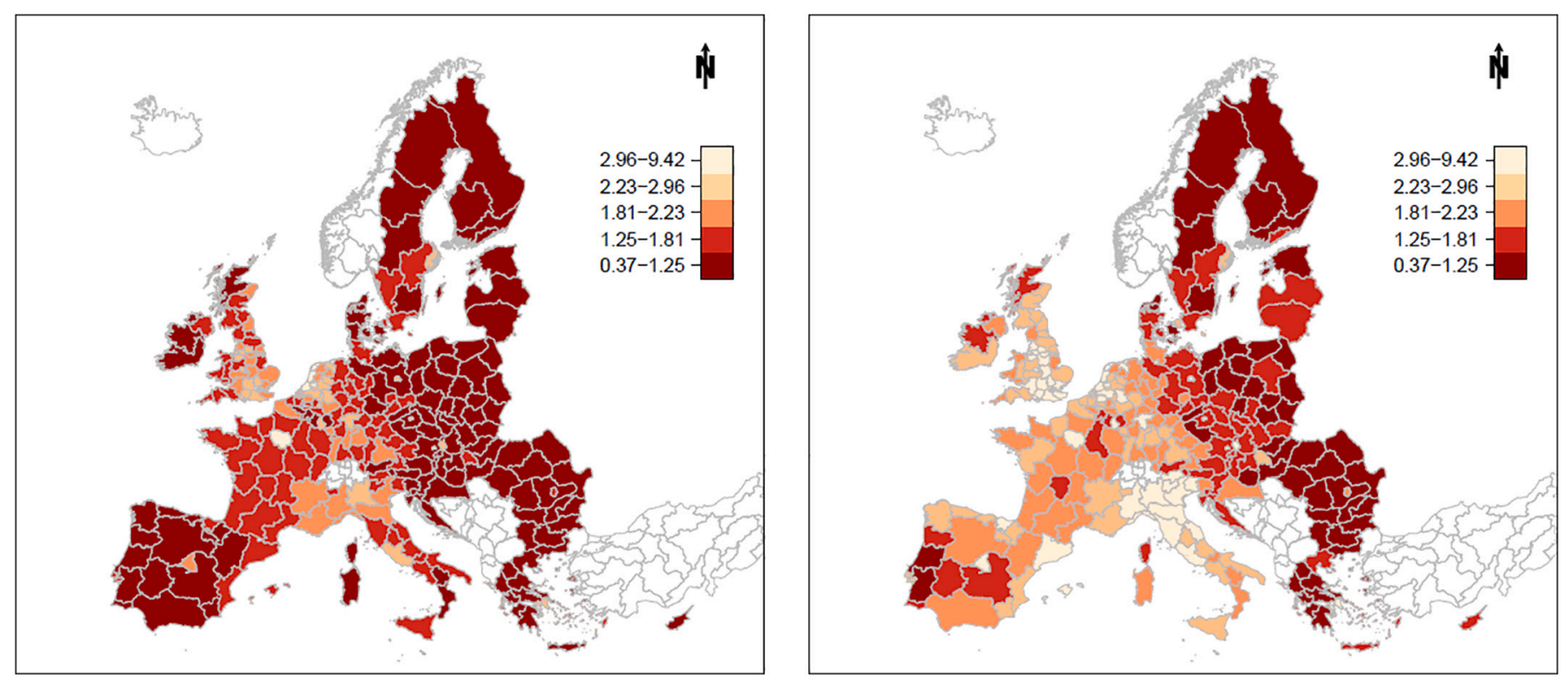

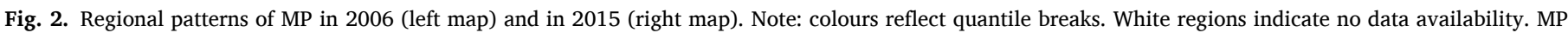
measured in PPS/Kg.

\subsection{Material productivity, socio-economic drivers and economic structures}

Table 3 shows the results obtained from approaches EXO and INT. In
EXO we treat the economic structures as exogenous variables, estimating their direct impact on material productivity. In this case, the use of the taxonomy of regional economic structures developed in section 3.1 is not suggested, as reliable fixed-effects estimation requires 
Table 3

Fixed-effects regression results for EXO and INT.*, **, $* * *$

\begin{tabular}{|c|c|c|c|c|}
\hline Coefficients & EXO & & INT & \\
\hline GDP & $0.713^{* * *}$ & $(0.06)$ & & \\
\hline $\mathrm{GDP}^{\wedge} 2$ & $-0.144 \%$ & $(0.07)$ & $-0.133^{* *}$ & $(0.07)$ \\
\hline Pop & $2.991^{* * *}$ & $(0.34)$ & & \\
\hline$R \& D$ & $0.175^{* * *}$ & $(0.03)$ & & \\
\hline $\mathrm{R} \& \mathrm{D}^{\wedge} 2$ & $0.041^{* * *}$ & $(0.01)$ & $0.038^{* * *}$ & $(0.01)$ \\
\hline LQ Agriculture & $0.110^{* * *}$ & $(0.03)$ & & \\
\hline LQ Industry & $0.396^{* * *}$ & $(0.13)$ & & \\
\hline LQ Service & $1.111^{* * *}$ & $(0.23)$ & & \\
\hline GDP: CL Agriculture & & & $0.630 * * *$ & $(0.07)$ \\
\hline GDP: CL Industry & & & $0.615^{* * *}$ & $(0.06)$ \\
\hline GDP: CL Intermediate & & & $0.546^{* * *}$ & $(0.06)$ \\
\hline GDP: CL Service & & & $0.554 * * *$ & $(0.06)$ \\
\hline Pop: CL Agriculture & & & $2.623^{* * *}$ & $(0.34)$ \\
\hline Pop: CL Industry & & & $2.673^{* * *}$ & $(0.34)$ \\
\hline Pop: CL Intermediate & & & $2.808^{* * *}$ & $(0.34)$ \\
\hline Pop: CL Service & & & $2.787^{* * *}$ & $(0.35)$ \\
\hline R\&D: CL Agriculture & & & $0.151^{* * *}$ & $(0.05)$ \\
\hline R\&D: CL Industry & & & $0.181^{* * *}$ & $(0.04)$ \\
\hline R\&D: CL Intermediate & & & $0.181^{* * *}$ & $(0.04)$ \\
\hline R\&D: CL Service & & & $0.135^{* * *}$ & $(0.05)$ \\
\hline $\mathrm{R}$ & 0.311 & & 0.278 & \\
\hline R2 & 0.228 & & 0.189 & \\
\hline F-statistic & 128.99 & & 62.79 & \\
\hline DF & 2288 & & 2282 & \\
\hline Poolability test (F test) & $21.70^{* * *}$ & & $20.29^{* * *}$ & \\
\hline Hausman test (chisq) & $523.38^{* * *}$ & & 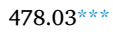 & \\
\hline Wooldridge's SC test (F test) & $1452^{* * *}$ & & $1366^{* * *}$ & \\
\hline Pesaran's CD test (z test) & $174.48^{* * *}$ & & $197.33^{* * *}$ & \\
\hline
\end{tabular}

Note: values in brackets refers to heteroskedasticity and serial (cross-sectional) robust standard errors (Arellano). Poolability test computes $\mathrm{F}$ tests of effects based on the comparison of the within and the pooling models. Wooldridge's SC test refers to the general serial correlation test in "short" panels. Pesaran's CD test refers to the global cross-sectional dependence test in "short" panels (see Croissant and Millo (2008) for test statistic description).

$$
\begin{aligned}
& { }^{*} p<0.1 . \\
& { }_{* * * *} p<0.05 . \\
& \quad p<0.01 .
\end{aligned}
$$

sufficient variability over time in the predictor variables (Hill et al., 2019). ${ }^{8}$ To overcome this limitation, we estimated EXO by directly applying the LQs. Being continuous variables, LQs can be effectively employed in fixed-effects models. Finally, in approach INT we applied the economic structures (as categorical variables) to the explanatory variables, generating four interaction terms for each socioeconomic driver. These interaction terms measure the influence of socioeconomic drivers on material productivity, according to the economic structures.

The two models present similar explanatory power (R-adjusted $\sim 0.2$ ) and all explanatory variables are significant and show the expected sign. The quadratic forms of GDP and R\&D behave in a consistent and similar fashion across the two models. A decreasing marginal utility is observed for GDP per capita $(\sim-0.14)$ and an increasing marginal utility is noted for $R \& D(\sim 0.04)$. Population density has the largest explanatory power $(>2.5)$ in all models. This means that, ceteris paribus, a $1 \%$ increase in population density would at least produce a $2.5 \%$ improvement in material productivity. This is in line with previous fixed-effect models that have promoted population density as the sole elastic socioeconomic driver for material consumption (West and Schandl, 2018). The second most relevant variable is GDP per capita, which shown an average coefficient value of 0.6 . This is fully consistent with the 0.56 and 0.60 scores proposed in Pothen and Welsch (2019) and Wiedmann et al. (2015), respectively.

Looking at the coefficients of LQs it emerges that specialisation in

\footnotetext{
${ }^{8}$ It should be considered that the cluster taxonomy is based on four categorical variables that are nearly constant. Therefore, they would not contribute much information to the analysis within a fixed-effects approach.
}

material-intensive economies can be considered an inelastic driver. In other words, further specialisation in agriculture or industrial economy leads to an improvement of MP of inferior magnitude. On the contrary, the relationship between service specialisation and material productivity is almost proportional, i.e. an $1 \%$ increase in service specialisation would produce roughly a $1.11 \%$ improvement in MP. As this is presumably the first study in which LQs are used as proxies for economic structure, we do not have a valid reference to compare the parameters. However, the estimated elasticities are consistent with the theoretical argumentation introduced by similar studies (Fernández-Herrero and Duro, 2019; Gan et al., 2013; Robaina et al., 2020), namely that servicebased economies are structurally advantaged when it comes to MP performance. However, differently from Fernández-Herrero and Duro and Gan et al., which found a negative relationship between MP and material-intensive structures, our LQ elasticities are all positive. Our interpretation is that higher degrees of economic specialisation may translate into productivity gains, thanks to advancements in technological capacity and know-how in the concerned market segments. In fact, the use of GVA shares as explanatory variable for MP - instead of LQs - 'penalises' the regions with higher concentrations of economic activity on material intensive sectors, ignoring that such regions are most likely those that show higher levels of competitivity and productivity in those same economic activities. In turn, the use of LQs allows to simultaneously characterise regional economic structures alongside their degree of specialisation, which is an important advantage of this approach over alternative options.

Several conclusions can be drawn by looking at model INT parameters. First of all, we observe a relevant difference in GDP per capita between material-intensive clusters ( 0.63 for agriculture and 0.62 industry) and intermediate and service regions (both 0.55 ). This seems to suggest that the more 'material-intensive regions' could be better placed to boost material productivity through increased levels of affluence. An opposite pattern is observed for population density. In this case, an increase in this indicator has a greater leverage effect on intermediate and service-based economies compared to the same increase happening in agriculture and/or industrial regions ( 2.81 for intermediate and 2.62 for agriculture). This suggests that the concentration of population favours greater levels of MP in urban economies, but not so much in rural and sparsely populated regions. In other words, there seems to be a synergetic effect between changes in population density (which increases material efficiency) and regional economic specialisation (i.e. increased service-orientation of regional economies leading to economic dematerialisation). Concerning the effect of R\&D expenditure on MP, we found a positive relationship. This seems reasonable as more investment in $R \& D$ can deliver goods and services more efficiently, and produce goods which have an increased knowledge component in their value added. However, R\&D impact is very marginal and presents little variation across the economic structures considered (0.14-0.18).

Finally, Table 4 presents the $T_{0}$ statistic results computed by linear hypothesis testing with heteroskedasticity and serial (cross-sectional) robust standard errors. According to this test, we can assert that the effect of GDP and POP on MP is significatively different between material intensive economies (i.e. agriculture and industry cluster) and the less material intensive economies (i.e. intermediate and service economies), while the same cannot be said for the impact of R\&D on MP, which does not change significantly across the economic structures considered.

\subsection{Robustness checks}

We conducted a number of checks to scrutinize whether our results are robust to potential endogeneity issues. Some authors caution that current MP levels might be affected by past levels of MP (Flachenecker, 2018; Robaina et al., 2020). The hypothesis that past values of technological levels influence present technological performance is plausible, as the technological trajectory of a given territory is the result of a long 
Table 4

Linear hypothesis testing results. Values refer to $T_{0}$ statistics computed considering heteroskedasticity and serial (cross-sectional) robust standard errors. *, **,

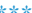

\begin{tabular}{|c|c|c|c|c|}
\hline & CL Agric & CL Industry & CL Interm. & CL Service \\
\hline \multicolumn{5}{|c|}{ Socioeconomic driver: GDP } \\
\hline CL Agric. & & 0.509 & $4.538 * *$ & $2.978^{*}$ \\
\hline CL Industry & 0.509 & & $5.013^{* *}$ & $2.798^{*}$ \\
\hline CL Interm. & $4.538 * *$ & $5.013 * *$ & & 0.165 \\
\hline CL Service & $2.978^{*}$ & $2.798^{*}$ & 0.165 & \\
\hline \multicolumn{5}{|c|}{ Socioeconomic driver: POP } \\
\hline CL Agric. & & 1.045 & $4.463^{* *}$ & $2.848^{*}$ \\
\hline CL Industry & 1.045 & & $4.698 * *$ & 2.320 \\
\hline CL Interm. & $4.463^{* *}$ & $4.698^{* *}$ & & 0.226 \\
\hline CL Service & $2.848^{*}$ & 2.320 & 0.226 & \\
\hline \multicolumn{5}{|c|}{ Socioeconomic driver: $R \& D$} \\
\hline CL Agric. & & 0.675 & 0.528 & 0.085 \\
\hline CL Industry & 0.675 & & 0 & 1.070 \\
\hline CL Interm. & 0.528 & 0 & & 1.239 \\
\hline CL Service & 0.085 & 1.070 & 1.239 & \\
\hline
\end{tabular}

$$
\begin{aligned}
& { }^{*} p<0.1 . \\
& { }^{* * *} p<0.05 . \\
& { }^{* * *} p<0.01 .
\end{aligned}
$$

historical process (Porter, 1990). In fact, MP has been often used as proxy indicator for technological level in cross-countries analyses (Dong et al., 2017; Schandl and West, 2010; Steinberger and Krausmann, 2011). Even if the use of lagged MP values has not been considered in recent EW-MFA STIRPAT applications (Fernández-Herrero and Duro, 2019; Gan et al., 2013; West and Schandl, 2018), we took into account potential issues of endogeneity by applying the difference-generalized method of moments (GMM) developed by Arellano and Bond (1991). Differently from the traditional "fixed-effect" econometric method, the difference-GMM is able to produce empirical output considering the dynamic relationship between variables and it also eliminates the problem of endogeneity and autocorrelation thanks to the use of the lagged values of explanatory variables as instrumental variables. GMM results did not reject our underlying hypothesis, namely that the nature of economic structures can influence the impact of socioeconomic drivers. Besides an overall reduction of the magnitude of elasticities due to the inclusion of MP(t-1) term, material-intensive regions (agricultural and industrial based economies) still present higher affluence elasticities (GDP per capita) compared to less material intensive regions (intermediate and service-based economies). In contrast, population density presented even higher leverage effects across services and intermediate regions compared to material intensive regions. As a result from this check, we have stuck to our simpler and more interpretable INT model.

Similarly to previous works (Flachenecker, 2018; Pothen and Welsch, 2019), we also tested the robustness of our empirical models (EXO \& INT) to potential exclusion of countries and/or periods of time. First, we dropped the period $2008-2010$ as this was characterised by a significant decline in economic output and material consumption levels. Second, we conducted the analysis for EU-15, to see whether the results might change considering only most advanced EU economies. ${ }^{9}$ This check also confirmed that our results are generally robust. The exclusion of the period 2008-2010 from the analysis seemed to only affect the magnitude of elasticities, but it did not affect the relationship among them, nor their significance. The major change produced by the exclusion of non-EU-15 from the sample was the loss of significance for the quadratic term of GDP. This change might be due to the reduced variation of GDP levels within the sample. In fact, as EU-15 present similar GDP levels, the explanatory power of this parameter could be affected.

\footnotetext{
${ }^{9}$ We also considered the exclusion of single years characterised by significant "jumps" in linear trends, such as 2008 and 2011, and the exclusion of the five regions having the highest GDP per capita and the 5 regions having the lowest GDP per capita.
}

The empirical results of robustness checks can be found in the supplementary material S1.

\section{Discussion}

Our findings provide compelling evidence that the use of economic structures as simple exogenous factors explaining MP falls short in providing a comprehensive picture of the relationship between material productivity and its determinants. In particular, the analysis showed that different structural economic configurations are likely to change the effect of GDP and POP on material productivity. To give an idea of the scale of such differences across regional clusters, we present in Fig. 3 the prediction of MP calculated by applying the values of interaction terms obtained in model INT. Each scatterplot represents the trends of MP calculated by using, respectively, the four elasticities obtained across economic structures for each socioeconomic driver (i.e. GDP, POP, and $\mathrm{R} \& \mathrm{D}$ ), while keeping the remaining parameters constant (the regression equations employed to generate the scatterplot are provided in the supplementary materials $\mathrm{S} 1$ ).

The influence of GDP and POP on MP varies considerably depending on the socioeconomic structures of regions. Concerning GDP elasticity and assuming other conditions being equal between economic structures, at a GDP per capita level equal to $€ 20,000$, material intensive economies would be about twice as resource productive than intermediate and service-based economies. Conversely, the different elasticity of POP across regional groupings implies that, at a population density of $200 \mathrm{hab} / \mathrm{Km}^{2}$, this factor would be associated with MP levels being 2.5 times higher in intermediate and service economies compared to material-intensive regions. Obviously, these predictions are only hypothetical, as the ceteris paribus assumption is not realistic. Furthermore, it should be borne in mind that the divergent effects observed between socioeconomic factors would largely offset each other, with a likely predominance of population density - as this variable presents greater elasticities in all types of regions. This also explains why very conglomerated areas such as metropolitan cities usually exhibit the highest MP scores (e.g. Brussels, Madrid or Ile de France).

The higher elasticity of GDP for agricultural and industrial regions might appear counterintuitive, considering that in general these regions show lower levels of MP. However, this is explained by the intrinsic physical nature of their economies. In fact, these regions are mainly producers and exporters of raw material and processed goods, so that an increase in affluence would have direct repercussion on their productive means. Production would be enhanced by a greater access to financial resources, and therefore to technological improvements. By contrast, a GDP increase in tertiary economies would have a smaller impact on material productivity, as these economies present a rather weak presence of manufacturing and/or raw material extraction activities. Conversely, population density presents a higher leverage effect in urban regions, where space constraints the deployment of materialintensive activities and favours instead the development of strong service-oriented economies. In addition, the significant difference of POP elasticity between denser (service-based regions) and less dense (agricultural and industrial regions) areas is consistent with previous findings, confirming that firms and workers are, on average, more productive in agglomerated economies (Combes et al., 2012; Duranton and Puga, 2014).

Interestingly, R\&D elasticities present a significant but marginal effect on MP, which does not change significantly across different types of regions. This could be explained by a combination of factors. On the one hand, investments in R\&D do not necessarily aim at increasing material efficiency. In fact, as described by Domenech and Bahn-Walkowiak (2019), green technologies only attract a small share of R\&D budgets. For instance, in Finland, which is the country that invests more resources on green innovation, green technologies attract only $12.5 \%$ of the total budget for R\&D. On the other hand, it should be noted that the impact of R\&D investment does not necessarily translate into local 

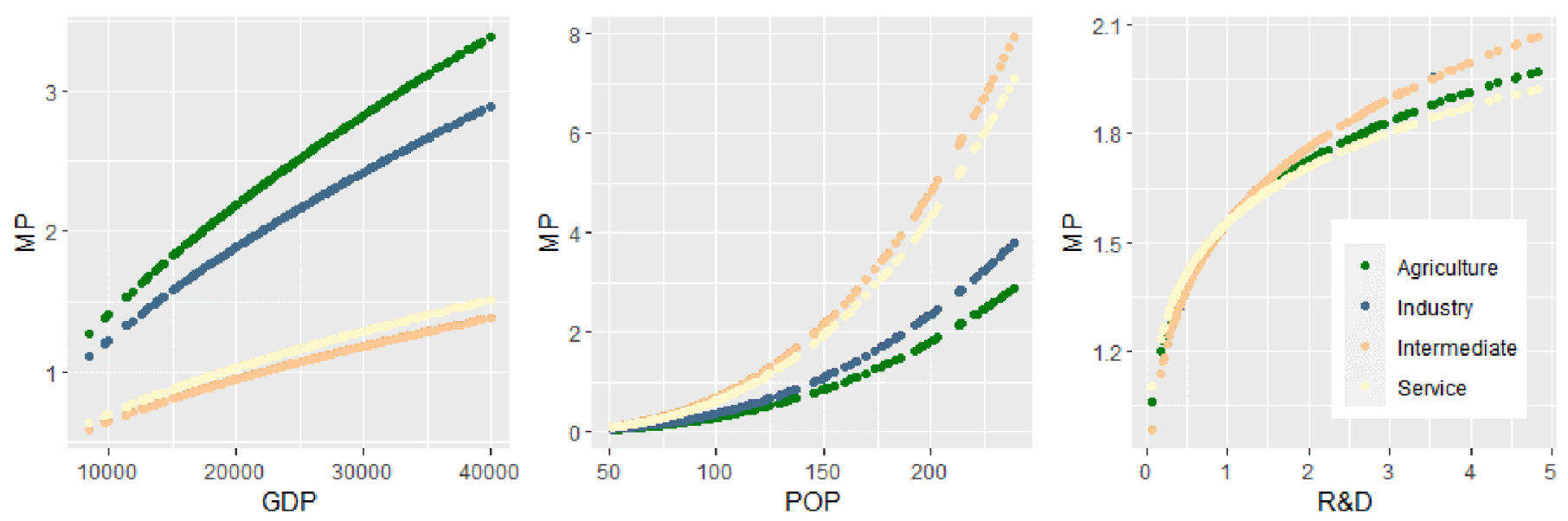

Fig. 3. Material productivity trends according to economic structures elasticities. Figures for GDP (PPS/hab), POP (hab/Km2) and R\&D (\%) refer to 2015.

impacts. Technological innovations often generate impacts in locations that are distant from the place where such innovations were designed. For example, technologies to increase material efficiency of industrial processes are seldom developed in the same areas where industrial plants are based.

A number of relevant policy messages emerge from our findings. Our models confirm that agricultural and industrial areas show greater potential for improving material productivity thanks to the concentration of material-intensive activities in those areas. This calls for investments on technologies and innovations aiming at material efficiency, particularly in material-intensive sectors and regions. However, we have seen how investments on green technologies still attract a small share of R\&D investments. At the same time, agricultural and industrial regions often experience underinvestments (Flachenecker and Rentschler, 2018), mostly due to their less dynamic markets (Bachtler et al., 2017). Hence, better access to finance in those areas would not only support resource productivity goals, but also mitigate the growing polarization between core and peripheral regions in Europe (Bassi and Durand, 2018; Lee and Luca, 2019). Another conclusion from our models is that the economies of scale in consumption clearly benefit MP. From this it can be inferred that spatial planning policies should promote urban densification, even in sparsely populated areas. In peripheral and shrinking regions, scaleappropriate systems will need to be re-formulated to support smaller population while land take should be minimised through compact urbanization (Williams, 2019). Regions with urban and service-oriented economies, which are typically those with a greater concentration of population, should focus on the adoption of innovations geared at the organisation and optimisation of urban life. In particular, changing consumption habits of those living in cities will be critical to decouple economic growth from resource consumption (Zaman and Lehmann, 2011). In this sense, urban agglomerations present the right conditions for the development of business models that are based on product sharing, pooling and other forms of collaborative consumption that may contribute to curb demand for raw materials at the source (Cohen and Muñoz, 2016).

\section{Conclusion}

Research on the effects that economic structures exert on the relationship between material productivity and socioeconomic factors has been historically neglected by EW-MFA studies. This paper argues that the idiosyncratic features of the individual regions, and therefore, the diverse economic configurations that the regions show, necessarily influence MP. Understanding the complex relationship between MP and its socioeconomic drivers under different structural economic configurations is essential for addressing current societal challenges and, hence, for providing policymakers with context-sensitive recommendations.
Our results provide evidence that the impact of socioeconomic drivers on material productivity changes according to the intrinsic socioeconomic structures of regions. In particular, affluence and population density impact the material productivity in considerably different ways based on the prevailing economic specialisation of regional economies. Areas relying on primary and secondary sectors present higher returns in MP from increased levels of affluence, compared to intermediate and service-based economies. By contrary, intermediate and service-based economies tend to increase material productivity through physical densification. Overall, population density has a greater influence on MP levels than affluence. Not surprisingly, regions with higher population density have higher material productivity levels.

From a methodological perspective, this work provides two novelties in relation to traditional STIRPAT approaches: (1) the use of LQs instead of the share of gross values added as parameter capturing the structure of regional economies; (2) the consideration of these structures as endogenous factors shaping the relationship between MP and socioeconomic drivers. LQs provide superior information on the economy of a region, as they also recognise the level of specialisation, which to some extent is related to material efficiency. Similarly, examining the socioeconomic drivers by considering the underlying economic structures offers critical insights into the leading MP leverages of territories. In general, our method increases the explanatory power of socioeconomic drivers on MP, enabling more detailed and place-specific interpretations of regression coefficients.

Our approach also opens-up several research avenues for the future, as it encourages the exploration of alternative endogenous structures of socioeconomic drivers. In this analysis, we considered economic structures resulting from regional economic specialisation, but other configurations might be considered. As an example, Liddle and Lung employed a STIRPAT approach to investigate the consumption-related environmental impacts by population age-structure (Liddle and Lung, 2010). Similarly, considering the aforementioned MP limits, other resource productivity measures could be employed to further expand the understanding of regional productivity levels. In this sense, Malmquist Productivity Index (MPI) could represent a promising approach since it not only allows to integrate several factors related to productivity, but also to decompose productivity into technical and efficiency components (Kumar, 2006; Mahlberg et al., 2011; Zhang et al., 2011). Likewise, access to improved regional data could open a number of additional channels of analysis, such as adding further explanatory variables better describing regional modes of consumption (e.g. import/ export shares, transport statistics, type of energy consumption etc.).

Ideally, the analysis presented here should be complemented by adopting a consumption perspective. In particular, the use of alternative material indicators such as Material Footprint (MF) could shed light on the extent to which final consumption drives MP differently from 
production-based indicators like DMC. As showed in Wiedmann et al. (2015), assessments frequently differ depending on which modelling approach and indicators are used. In general, since MF indicators focus on final consumption, regional economic structures become less prominent drivers of MP. The production perspective adopted in this research seems more appropriate for identifying the role of territorial features on MP. Our main conclusion is that MP gains should be sought through efficiency improvements rather than structural economic transformations. Even if a shift towards increased service economies would automatically lead to improved -DMC-based- levels of MP, in most European regions this would be neither feasible nor desirable. In fact, most areas lack the critical mass required by such transformations, including access to human, technological and financial capitals. Similarly, the extent to which material-intensive activities such as mining and forestry can be localised in a given territory is also conditioned by its intrinsic characteristics, among which resource availability is the most obvious expression. Moreover, material-intensive activities, such as manufacturing, contribute to increase regional and national economic resilience. These activities make a very significant contribution to regional economies and, by localising and visualising the positive and negative externalities of massive resource use, they indirectly increase demand for new technologies and innovations that may further reinforce economic resilience and the overall economic dynamism of regions.

\section{Funding}

This research did not receive any specific grant from funding agencies in the public, commercial, or not-for-profit sectors.

\section{Declaration of Competing Interest}

The authors declare that they have no known competing financial interests or personal relationships that could have appeared to influence the work reported in this paper.

\section{Acknowledgements}

The authors are grateful to three anonymous referees for their constructive comments and suggestions. Any remaining errors are solely the authors' responsibility.

\section{Appendix A. Supplementary data}

Supplementary data to this article can be found online at https://doi. org/10.1016/j.ecolecon.2021.106948.

\section{References}

Akenji, L., Bengtsson, M., 2014. Making sustainable consumption and production the core of sustainable development goals. Sustain. 6, 513-529. https://doi.org/ $10.3390 /$ su6020513.

Arellano, Manuel, Bond, Stephen, 1991. Some tests of specification for panel data: Monte Carlo evidence and an application to employment equations. Rev. Econ. Stud. 58, 277-297.

Bachtler, J., Martins, J.O., Wostner, P., Zuber, P., 2017. Towards Cohesion Policy 4.0 Structural Transformation and Inclusive Growth.

Bassi, F., Durand, C., 2018. Crisis in the European monetary union: a Core-periphery perspective. Econ. Polit. 35, 251-256. https://doi.org/10.1007/s40888-018-0094-6.

Behrens, A., Giljum, S., Kovanda, J., Niza, S., 2007. The material basis of the global economy. Ecol. Econ. 64, 444-453. https://doi.org/10.1016/j. ecolecon.2007.02.034.

Bianchi, M., Tapia, C., del Valle, I., 2020a. Monitoring domestic material consumption at lower territorial levels: a novel data downscaling method. J. Ind. Ecol. https://doi. org/10.1111/jiec.13000.

Bianchi, M., del Valle, I., Tapia, C., 2020b. Measuring eco-efficiency in European regions: evidence from a territorial perspective. J. Clean. Prod. 123246 https://doi.org/ 10.1016/j.jclepro.2020.123246.

Bravo-Ortega, C., García Marín, Á., 2011. R\&D and productivity: a two way avenue? World Dev. 39, 1090-1107. https://doi.org/10.1016/j.worlddev.2010.11.006.

Bringezu, S., Schütz, H., Steger, S., Baudisch, J., 2004. International comparison of resource use and its relation to economic growth: the development of total materia requirement, direct material inputs and hidden flows and the structure of TMR. Ecol. Econ. 51, 97-124. https://doi.org/10.1016/j.ecolecon.2004.04.010.

Brock, G., Pihur, V., Datta, S., Datta, S., 2008. ClValid: an R package for cluster validation. J. Stat. Softw. 25, 1-22. https://doi.org/10.18637/jss.v025.i04.

Castelnovo, P., Morretta, V., Vecchi, M., 2020. Regional disparities and industrial structure: territorial capital and productivity in Italian firms. Reg. Stud. https://doi. org/10.1080/00343404.2020.1763941.

Cohen, B., Muñoz, P., 2016. Sharing cities and sustainable consumption and production: towards an integrated framework. J. Clean. Prod. 134, 87-97. https://doi.org/ 10.1016/j.jclepro.2015.07.133.

Combes, Pierre-Philippe, Duranton, G., Gobillon, L., Puga, D., Roux, S., 2012. The productivity advantages of large cities: distinguishing agglomeration from firm selection. Econometrica 80, 2543-2594. https://doi.org/10.3982/ecta8442.

Croissant, Y., Millo, G., 2008. Panel data econometrics in R: the plm package. J. Stat. Softw. 27, 1-43. https://doi.org/10.18637/jss.v027.i02.

Cutrini, E., 2019. Economic integration, structural change, and uneven development in the European Union. Struct. Chang. Econ. Dyn. 50, 102-113. https://doi.org/ 10.1016/j.strueco.2019.06.007.

Dietz, T., Rosa, E.A., 1994. Rethinking the environmental impacts of population, affluence and technology. Hum. Ecol. Rev. 1, 277-300.

Dietz, T., Rosa, E.A., 1997. Effects of population and affluence on $\mathrm{CO} 2$ emissions. Proc. Natl. Acad. Sci. U. S. A. 94, 175-179. https://doi.org/10.1073/pnas.94.1.175.

Dietz, T., Rosa, E.A., York, R., 2007. Driving the human ecological footprint. Front. Ecol. Environ. 5, 13-18. https://doi.org/10.1890/1540-9295(2007)5[13:DTHEF]2.0.CO; 2

Dittrich, M., Giljum, S., Polzin, C., Bringezu, S., 2011. Resource use and resource efficiency in emerging economies. In: Trends Over the Past 20 Years.

Domenech, T., Bahn-Walkowiak, B., 2019. Transition towards a resource efficient circular economy in Europe: policy lessons from the EU and the member states. Ecol. Econ. 155, 7-19. https://doi.org/10.1016/j.ecolecon.2017.11.001.

Dong, L., Dai, M., Liang, H., Zhang, N., Mancheri, N., Ren, J., Dou, Y., Hu, M., 2017. Material flows and resource productivity in China, South Korea and Japan from 1970 to 2008: a transitional perspective. J. Clean. Prod. 141, 1164-1177. https://doi.org/ 10.1016/j.jclepro.2016.09.189.

Dunn, J.C., 1974. Well-separated clusters and optimal fuzzy partitions. J. Cybern. 4, 95-104. https://doi.org/10.1080/01969727408546059.

Duranton, G., Puga, D., 2014. Chapter 5 - the growth of cities. In: Handbook of Economic Growth, pp. 781-853. https://doi.org/10.1016/B978-0-444-53540-5.00005-7.

European Commission, 2013. Manual on Regional Accounts Methods Manuals and Guidelines. https://doi.org/10.2785/33649.

EUROSTAT, 2018. Economy-Wide Material Flow Accounts HANDBOOK. https://doi.org/ 10.2785/158567.

Feenstra, R., Kee, H.L., 2008. Export variety and country productivity: estimating the monopolistic competition model with endogenous productivity. J. Int. Econ. 74, 500-518. https://doi.org/10.1016/j.jinteco.2006.11.006.

Fernández-Herrero, L., Duro, J.A., 2019. What causes inequality in material productivity between countries? Ecol. Econ. 162, 1-16. https://doi.org/10.1016/j. ecolecon.2019.04.007.

Fischer-Kowalski, M., Haberl, H., 1998. Sustainable development: socioeconomic metabolism and colonization of nature. Int. Soc. Sci. J. 50, 573-587. https://doi.org/ 10.1111/1468-2451.00169.

Fischer-Kowalski, M., Hüttler, W., 1998. Society's metabolism: the intellectual history of materials flow analysis, part II, 1970-1998. J. Ind. Ecol. 2, 107-136. https://doi.org/ 10.1162/jiec.1998.2.4.107.

Flachenecker, F., 2018. The causal impact of material productivity on macroeconomic competitiveness in the European Union. Environ. Econ. Policy Stud. 20, 17-46. https://doi.org/10.1007/s10018-016-0180-3.

Flachenecker, F., Rentschler, J., 2018. Investing in Resource Efficiency: The Economics and Politics of Financing the Resource Transition. Springer. https://doi.org/ 10.1007/978-3-319-78867-8.

Frenken, K., Van Oort, F., Verburg, T., 2007. Related variety, unrelated variety and regional economic growth. Reg. Stud. 41, 685-697. https://doi.org/10.1080/ 00343400601120296.

Gan, Y., Zhang, T., Liang, S., Zhao, Z., Li, N., 2013. How to Deal with resource productivity. J. Ind. Ecol. 17, 440-451. https://doi.org/10.1111/j.15309290.2012.00547.x.

Giljum, S., Dittrich, M., Lieber, M., Lutter, S., 2014. Global patterns of material flows and their socio-economic and environmental implications: a MFA study on all countries world-wide from 1980 to 2009. Resources 3, 319-339. https://doi.org/10.3390/ resources3010319.

Gräbner, C., Heimberger, P., Kapeller, J., Schütz, B., 2019. Structural change in times of increasing openness: assessing path dependency in European economic integration. J. Evol. Econ. https://doi.org/10.1007/s00191-019-00639-6.

Handl, J., Knowles, J., Kell, D.B., 2005. Computational cluster validation in post-genomic data analysis. Bioinformatics. https://doi.org/10.1093/bioinformatics/bti517.

Hassink, R., Klaerding, C., 2015. Evolutionary approaches to local and regional development policy. In: Handbook of Local and Regional Development. https://doi. org/10.4324/9780203842393.ch12.

Hill, T.D., Davis, A.P., Roos, J.M., French, M.T., 2019. Limitations of fixed-effects models for panel data. Sociol. Perspect. https://doi.org/10.1177/0731121419863785.

Kancs, D'artis, Siliverstovs, B., 2016. R\&D and non-linear productivity growth. Res. Policy 45, 634-646. https://doi.org/10.1016/j.respol.2015.12.001.

Kovanda, J., Weinzettel, J., 2013. The importance of raw material equivalents in economy-wide material flow accounting and its policy dimension. Environ. Sci. Pol. 29, 71-80. https://doi.org/10.1016/j.envsci.2013.01.005. 
Krausmann, F., Fischer-Kowalski, M., Schandl, H., Eisenmenger, N., 2008. The global sociometabolic transition: past and present metabolic profiles and their future trajectories. J. Ind. Ecol. 12, 637-656. https://doi.org/10.1111/j.15309290.2008.00065.x.

Krausmann, F., Haas, W., Schandl, H., Fishman, T., Haberl, H., Tanikawa, H., Wiedenhofer, D., Miatto, A., Lauk, C., 2017. Global socioeconomic material stocks rise 23 -fold over the 20th century and require half of annual resource use. Proc. Natl. Acad. Sci. 114, 1880-1885. https://doi.org/10.1073/pnas.1613773114.

Kumar, S., 2006. Environmentally sensitive productivity growth: a global analysis using Malmquist-Luenberger index. Ecol. Econ. 56, 280-293. https://doi.org/10.1016/j. ecolecon.2005.02.004.

Lahti, L., Huovari, J., Kainu, M., Biecek, P., 2019. Retrieval and analysis of Eurostat open data with the eurostat package. R J. 9, 385. https://doi.org/10.32614/rj-2017-019.

Lee, J., 2011. Export specialization and economic growth around the world. Econ. Syst. 35, 45-63. https://doi.org/10.1016/j.ecosys.2010.11.002.

Lee, N., Luca, D., 2019. The big-city bias in access to finance: evidence from firm perceptions in almost 100 countries. J. Econ. Geogr. 19, 199-224. https://doi.org/ $10.1093 / \mathrm{jeg} / \mathrm{lbx} 047$.

Liddle, B., Lung, S., 2010. Age-structure, urbanization, and climate change in developed countries: revisiting STIRPAT for disaggregated population and consumption-related environmental impacts. Popul. Environ. 31, 317-343. https://doi.org/10.1007/ s11111-010-0101-5.

Mahlberg, B., Luptacik, M., Sahoo, B.K., 2011. Examining the drivers of total factor productivity change with an illustrative example of $14 \mathrm{EU}$ countries. Ecol. Econ. 72, 60-69. https://doi.org/10.1016/j.ecolecon.2011.10.001.

Morretta, V., Syrett, S., Ramirez, L.S., 2020. Territorial capital as a source of firm competitive advantage: evidence from the north and south of Italy. Eur. Plan. Stud. https://doi.org/10.1080/09654313.2020.1722067.

OECD, 2011. Resource Productivity in the G8 and the OECD a Report in the Framework of the Kobe 3R. OECD.

Porter, M., 1990. Competitive advantage of nations. Compet. Intell. Rev. 1, 14. https:// doi.org/10.1002/cir.3880010112.

Pothen, F., Welsch, H., 2019. Economic development and material use. Evidence Int. Panel Data. World Dev. 115, 107-119. https://doi.org/10.1016/j. worlddev.2018.06.008.

R Core Team, 2020. A Language and Environment for Statistical Computing. R Found. Stat. Comput.. https://www.R-project.org

Robaina, M., Villar, J., Pereira, E.T., 2020. The determinants for a circular economy in Europe. Environ. Sci. Pollut. Res. https://doi.org/10.1007/s11356-020-07847-9.

Rousseeuw, P.J., 1987. Silhouettes: a graphical aid to the interpretation and validation of cluster analysis. J. Comput. Appl. Math. 20, 53-65. https://doi.org/10.1016/0377 0427(87)90125-7.

Schandl, H., West, J., 2010. Resource use and resource efficiency in the Asia-Pacific region. Glob. Environ. Chang. 20, 636-647. https://doi.org/10.1016/j. gloenvcha.2010.06.003.
Steffen, W., Richardson, K., Rockström, J., Cornell, S.E., Fetzer, I., Bennett, E.M., Biggs, R., Carpenter, S.R., De Vries, W., De Wit, C.A., Folke, C., Gerten, D., Heinke, J., Mace, G.M., Persson, L.M., Ramanathan, V., Reyers, B., Sörlin, S., 2015. Planetary boundaries: guiding human development on a changing planet. Science 80, 347. https://doi.org/10.1126/science.1259855.

Steger, S., Bleischwitz, R., 2011. Drivers for the use of materials across countries. J. Clean. Prod. 19, 816-826. https://doi.org/10.1016/j.jclepro.2010.08.016.

Stehrer, R., Stöllinger, R., 2015. The Central European Manufacturin Core: What is Driving Regional Production Sharing? FIW Res. Reports No. 2014/1.

Steinberger, J.K., Krausmann, F., 2011. Material and energy productivity. Environ. Sci. Technol. 45, 1169-1176. https://doi.org/10.1021/es1028537.

Steinberger, J.K., Krausmann, F., Eisenmenger, N., 2010. Global patterns of materials use: a socioeconomic and geophysical analysis. Ecol. Econ. 69, 1148-1158. https:// doi.org/10.1016/j.ecolecon.2009.12.009.

Steinberger, J.K., Krausmann, F., Getzner, M., Schandl, H., West, J., 2013. Development and dematerialization: an international study. PLoS One 8. https://doi.org/10.1371/ journal.pone.0070385.

Teixidó-Figueras, J., Steinberger, J.K., Krausmann, F., Haberl, H., Wiedmann, T., Peters, G.P., Duro, J.A., Kastner, T., 2016. International inequality of environmental pressures: decomposition and comparative analysis. Ecol. Indic. 62, 163-173. https://doi.org/10.1016/j.ecolind.2015.11.041.

Weisz, H., Krausmann, F., Amann, C., Eisenmenger, N., Erb, K.H., Hubacek, K., FischerKowalski, M., 2006. The physical economy of the European Union: cross-country comparison and determinants of material consumption. Ecol. Econ. 58, 676-698. https://doi.org/10.1016/j.ecolecon.2005.08.016.

West, J., Schandl, H., 2018. Explanatory variables for National Socio-Metabolic Profiles and the question of forecasting National Material Flows in a globalized economy. J. Ind. Ecol. 22, 1451-1464. https://doi.org/10.1111/jiec.12671.

Wiedmann, T.O., Schandl, H., Lenzen, M., Moran, D., Suh, S., West, J., Kanemoto, K., 2015. The material footprint of nations. Pnas 112, 6271-6276. https://doi.org/ 10.1073/pnas.1220362110.

Williams, J., 2019. Circular cities. Urban Stud. 56, 2746-2762. https://doi.org/10.1177/ 0042098018806133.

York, R., Rosa, E.A., Dietz, T., 2003. STIRPAT, IPAT and ImPACT: analytic tools for unpacking the driving forces of environmental impacts. Ecol. Econ. 46, 351-365. https://doi.org/10.1016/S0921-8009(03)00188-5.

Zaman, A.U., Lehmann, S., 2011. Challenges and Opportunities in Transforming a City into a "Zero Waste City.". Challenges 2, 73-93. https://doi.org/10.3390/ challe2040073.

Zhang, C., Liu, H., Bressers, H.T.A., Buchanan, K.S., 2011. Productivity growth and environmental regulations - accounting for undesirable outputs: analysis of China's thirty provincial regions using the Malmquist-Luenberger index. Ecol. Econ. 70, 2369-2379. https://doi.org/10.1016/j.ecolecon.2011.07.019.

Zhang, C., Chen, W.Q., Ruth, M., 2018. Measuring material efficiency: a review of the historical evolution of indicators, methodologies and findings. Resour. Conserv. Recycl. 132, 79-92. https://doi.org/10.1016/j.resconrec.2018.01.028. 